\title{
Trabalho, globalização e contramovimentos: dinâmicas da ação coletiva do precariado artístico no Brasil e em Portugal
}

\section{Resumo}

O artigo pretende comparar a formação do "precariado artístico" no Brasil e em Portugal, a partir da análise dos padrões de proletarização do trabalho de produção cultural nos dois países e sua relação com diferentes trajetórias de ação coletiva dos novos movimentos de trabalhadores precarizados. Assim, destacaremos o dilema enfrentado pelo movimento dos trabalhadores precários para transnacionalizar suas formas de ação coletiva. No caso brasileiro, analisamos, especificamente, a mobilização por políticas públicas para a cultura empreendida pelo movimento "Arte contra a Barbárie" que, distante do sindicalismo, desembocou na conquista do programa paulistano de Fomento ao Teatro. No caso português, investigamos a ação coletiva que se consolidou com a criação do sindicato-movimento "Cena" contra a perda de direitos trabalhistas, num contexto marcado pela adoção pelo governo português de políticas de austeridade negociadas com a União Europeia. Os limites da transnacionalização das reivindicações desses grupos de trabalhadores precários serão problematizados à luz da ideia, muito presente nos novos estudos "neopolanyianos" do trabalho, de que o processo de mobilização do precariado no Sul global anunciaria o advento de um contramovimento "embrionário", cuja tendência seria florescer conforme a mercantilização neoliberal ampliasse as ameaças à classe trabalhadora em escala mundial.

Palavras-chave: Precariado. Movimento dos trabalhadores. Ação sindical. Mercantilização do trabalho.

* Universidade de São Paulo, Brasil. 


\title{
Work, globalization, and countermovents: dynamics of collective action by the arts precariat in Brazil and Portugal
}

\begin{abstract}
The article aims to compare the formation of an "artistic precariat" in both Brazil and Portugal, by analyzing the patterns of proletarianization of cultural production in both countries and its relation with different trajectories of collective action by new movements lead by precarious workers. Thus, we highlight the dilemma faced by precarious workers movement to transnationalize their forms of collective action. In the Brazilian case, we have particularly analyzed the actions by the movement "Arte contra a Barbárie" demanding public policies in support of culture, which staying aloof from syndicalism attained a new legislation for fostering theater in the city of São Paulo. In Portugal, we have researched the collective action that led to the creation of union-movement called "Cena" that fought against the loss of labor rights, in a context marked by the adoption of austerity measures taken by the Portuguese government in agreement with the European Union. The limits to the transnationalization of the claims of these precarious workers' groups in both countries will be problematized in the light of the idea, which is very present in the new "neopolanyian" studies of labor, that the process of mobilization of precarious workers in the global South would point to the advent of an "embryonic" countermovement that would tend to burgeon as neoliberal commodification expands the threats to the working class on a world scale.
\end{abstract}

Keywords: Precariat. Labor movement. Labor union action. Commodification of work. 


\section{Introdução}

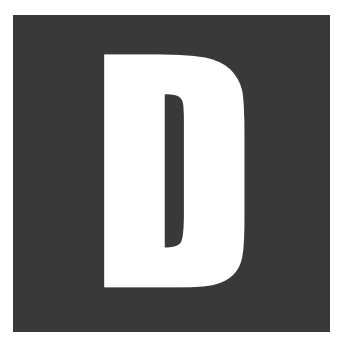

esde os anos 1980, a evolução da globalização neoliberal alçou ao primeiro plano a questão social nas sociedades capitalistas, já que estas têm deixado sistematicamente uma parte crescente de suas populações à margem dos direitos sociais, enquanto, no extremo oposto, a concentração de riquezas ampliou-se, sobretudo, por meio da "acumulação por espoliação" dos direitos sociais (Harvey, 2016). Essa situação histórica tem desafiado a tradicional interpretação do trabalho como espaço privilegiado de desenvolvimento de solidariedades e de formação de sujeitos políticos. Além disso, o neoliberalismo tem desafiado as forças sociais do trabalho a responderem ao desmanche dos direitos da cidadania, em especial, aqueles ligados mais diretamente à cidadania salarial.

Nesse contexto, muitos analistas têm destacado o enfraquecimento do sindicalismo fordista apoiado na fração adulta, branca, masculina e nacional da classe trabalhadora dos países capitalistas avançados (Beaud; Pialoux, 2009). A situação geral de avanço da mercantilização do trabalho somada à globalização econômica redefiniu o campo da sociologia do trabalho, alçando ao primeiro plano os chamados estudos do trabalho global. A fim de interpretar os limites e os alcances no desafio de interpretar as novas configurações dos movimentos sociais trabalhistas, esses estudos deslocaram seu foco das estratégias sindicais burocráticas, balizadas exclusivamente pelo Estado nação, para as mudanças na ação coletiva das forças sociais do trabalho em um contexto marcadamente globalizado (ver Evans, 2014; Bieler; Lindberg, 2010; Agarwala, 2013).

Daí a ênfase nos novos parâmetros da organização do trabalho e nos repertórios emergentes de mobilização capazes de esboçar um "contramovimento polanyiano" à privatização, à mercantilização e à liberaliza- 
ção do trabalho ${ }^{1}$. No entanto, e este é um traço saliente desses estudos, ao contrário do que ocorreu logo após o sucesso das manifestações contra o encontro da Organização Mundial do Comércio (OMC), em Seattle, em 30 de novembro de 1999 - quando alguns estudiosos do trabalho passaram a destacar a arena global, em detrimento do contexto nacional, como prioritária para apreender a renovação das dinâmicas da ação coletiva do trabalho -, os novos estudos do trabalho enfatizam a centralidade da relação entre os contextos global e nacional, a fim de compreender as questões emergentes do trabalho na globalização (Burawoy, 2010).

\section{Trabalho, globalização e contramovimentos}

Em certa medida, a etapa contemporânea dos estudos do trabalho global precisou acertar contas com o entusiasmo que se acendeu entre os pesquisadores com o advento do Fórum Social Mundial (FSM), cuja primeira edição foi realizada em Porto Alegre, em 2001. Na realidade, o fascínio despertado entre os estudiosos do movimento operário pelo livro de Polanyi (2000) deve ser interpretado a partir das afinidades eletivas existentes entre, de um lado, os alcances e os limites heurísticos do pensamento do autor e, de outro, a conjuntura política inaugurada em 2001 na cidade de Porto Alegre (Seoane; Taddei, 2002).

De Seattle a Porto Alegre, contramovimentos espontâneos estariam emergindo pragmaticamente na esteira da nova onda de mercantilização trazida pela globalização. Assim, somados, o aumento da feminização da força de trabalho, as diferentes formas de flexibilização e o aumento da

\footnotetext{
${ }^{1}$ Para Karl Polanyi (2000), o contramovimento produzido pelas forças sociais do trabalho teria se enraizado, nos anos 1930, tanto no fascismo europeu como no socialismo soviético, alcançando o bastião da economia de mercado, os Estados Unidos, em 1933. Por meio de uma combinação de políticas públicas que buscavam aliviar a situação dos trabalhadores desempregados pela depressão econômica, durante a década de 1930, o novo modelo de desenvolvimento fordista teria destroçado a regulação mercantil nos Estados Unidos.
} 
informalidade verificados em escala global serviriam para aproximar objetivamente os interesses dos trabalhadores do Norte e do Sul globalizados, possibilitando uma retomada do processo de internacionalização das práticas solidárias. Trata-se de um diagnóstico que não apenas afirmou a existência do contramovimento à mercantilização como, em acréscimo, associou-o à tradição internacionalista do movimento operário (Santos; Costa, 2005).

Apesar da fragilidade dos indícios empíricos atestando o surgimento desse contramovimento, o argumento predominante nos estudos da classe trabalhadora global é o de que as próprias contradições do desenvolvimento capitalista produzirão, mais cedo ou mais tarde, as bases para a internacionalização política da classe operária (Braga; Santana, 2015). E, com a retomada das mobilizações dos trabalhadores, o movimento sindical irá progressivamente recuperar seu protagonismo no interior do contramovimento do século XXI. No entanto, a frequência com que a experiência do FSM é citada pela literatura como exemplo bem-sucedido de contramovimento em escala global já indica a fragilidade dessa conjectura.

Um balanço desapaixonado do FSM revela tratar-se do início de estruturação de uma agenda global, e não de uma experiência de regulação social em larga escala. Afinal, é notório que a direção majoritária do FSM se esforçou para manter o encontro como um "espaço aberto" de debates, em vez de uma ferramenta organizativa com determinadas finalidades estratégicas. Uma "utopia real" - para utilizarmos o conceito de Erik Olin Wright (2010) - como o fórum não deve ser confundida com a experiência histórica de enraizamento dos mercados na sociedade.

De fato, após o início da crise da globalização e o relativo malogro das coalizões globais entre sindicatos, organizações não governamentais (ONG), agrupamentos de esquerda e movimentos sociais, inspiradas na experiência do FSM, os estudos do trabalho adentraram um período de 
certa polarização entre aqueles que seguiram enfatizando a importância de uma mudança de escala nas análises do trabalho, com foco nas dinâmicas globais, e aqueles um tanto ou quanto céticos no que diz respeito à importância da dimensão global na explicação dos movimentos trabalhistas (Waterman, 2001; Burawoy, 2010; Braga; Santana, 2015).

Entre esses dois polos, organizou-se um campo investigativo que, além de destacar a centralidade da escala nacional, sobretudo a relação entre o Estado e os movimentos trabalhistas na estruturação da escala global, tem buscado compreender o fenômeno da transnacionalização do trabalho, a partir de uma posicionalidade sociológica enraizada no Sul global. Assim, tais estudos almejam construir uma análise mais apurada dos entraves erguidos por coalizões políticas nacionais dominadas pelo capital financeiro globalizado aos projetos de construção de formas de solidariedade classista em escala internacional (Seidman, 2008).

Aqui, cabe observar que, para além da simples dimensão geográfica, interpretamos o Sul global como uma metáfora da espoliação social capaz de agregar tanto os processos de exploração nacional dirigidos pelas forças da financeirização do capital, quanto as lutas por projetos alternativos de transformação social e política. Ademais, a expressão "Sul global" refere-se a uma maneira de localizar as lutas sociais que ocorrem em regiões e países semiperiféricos submetidos às políticas de espoliação social impostas pela globalização financeira. Ou, nas palavras de Vijay Prashad:

O Sul global surgiu da concatenação de protestos contra a espoliação do bem comum, contra o roubo da dignidade humana e dos direitos, contra o enfraquecimento das instituições democráticas e das promessas da modernidade. $O$ Sul global é isso: um mundo de protestos, um furacão de atividades criativas. Esses protestos produziram uma abertura cuja direção política não é fácil de definir (2012, p. 18) 
Em síntese, entendemos que a expressão "Sul global" contém uma dimensão explicitamente política, atada aos protestos e às denúncias das relações de exploração, opressão e espoliação impostas pelo Norte global à semiperiferia do sistema, os quais intensificaram as tensões entre a forma democrática da regulação política e a dimensão autoritária do regime de acumulação financeirizado. Essa tensão tem estimulado diferentes movimentos sociais de contestação à atual globalização capitalista (15-M, Que se Lixe a Troika! etc.), lembrando, ainda que remotamente, o alvorecer daqueles contramovimentos de resistência aos avanços da mercantilização descritos por Polanyi para o período do entre guerras.

Nesse sentido, esses novos movimentos sociais protagonizados por jovens trabalhadores desempregados - ou subempregados - representam um desafio à tensão entre regulação política e acumulação econômica, promovido, sobretudo, pelo aprofundamento da mercantilização do trabalho. De fato, o desenvolvimento desse processo tem se mostrado uma fonte tanto de precarização da condição proletária como de estímulo ao surgimento de contramovimentos sociais em escala nacional. Nesses termos, é possível identificar um decidido investimento dos estudos do trabalho global na análise dos novos repertórios mobilizados pelas forças sociais do trabalho no sentido de resistir à desconstrução das formas tradicionais de solidariedade fordista e do enfraquecimento do poder sindical (Braga; Santana, 2015).

Inegavelmente, a dialética da mercantilização do trabalho transformou-se em um grande objeto investigativo. Afinal, a financeirização da economia promoveu o fechamento de fábricas e a redução do número de empregos qualificados nas economias capitalistas avançadas, empurrando os jovens rumo a ocupações desprotegidas, ao mesmo tempo em que acelerou a ampliação de uma força de trabalho sub-remunerada e insegura nos países semiperiféricos. Nosso argumento geral é que o cres- 
cimento do precariado nos países do Sul global estressou a regulação burocrática criada pelos Estados nacionais e pelo sindicalismo tradicional para absorver os antagonismos classistas nos limites da cidadania salarial, multiplicando conflitos insolúveis no interior do regime de acumulação pós-fordista e financeirizado.

Aqui, cabe destacar que por "precariado" entendemos o proletariado precarizado, ou seja, excluídos tanto o lumpemproletariado quanto a população pauperizada, aquele segmento da classe trabalhadora que Marx chamou de "superpopulação relativa". Essa definição parece-nos adequada, por três razões principais. Em primeiro lugar, ela permite-nos localizar o precariado no coração do próprio modo de produção capitalista e não como um subproduto da crise do modo de desenvolvimento fordista. Em segundo lugar, ela enfatiza a dimensão histórica e relacional desse grupo como parte integrante da classe trabalhadora, e não como um amálgama intergeracional e policlassista que assumiria de maneira progressiva a aparência de uma nova classe. Em terceiro lugar, em vez de retirar arbitrariamente a insegurança da relação salarial, essa noção possibilita-nos tratar a precariedade como uma dimensão intrínseca ao processo de mercantilização do trabalho.

Ademais, devemos diferenciar analiticamente o pauperismo (e o lumpemproletariado) do precariado, pois entendemos que os trabalhadores precários são uma parte da classe trabalhadora em permanente trânsito entre a possibilidade da exclusão social e o aprofundamento da exploração econômica. A necessidade de definir os limites gerais do precariado obriga-nos, também, a diferenciá-lo dos setores profissionais, ou seja, aqueles grupos mais qualificados, mais bem remunerados e, por isso mesmo, tendencialmente mais estáveis, da classe trabalhadora. Em suma, identificamos o precariado com a fração mais mal paga e explorada do proletariado urbano e dos trabalhadores agrícolas, excluídos a população 
pauperizada e o lumpemproletariado, por considerá-la própria à reprodução do capitalismo semiperiférico.

Em nossa opinião, o estudo do precariado no Sul global é capaz de revelar algumas dimensões centrais da reprodução contraditória do neoliberalismo. Assim, por meio da abordagem comparativa entre o processo de mobilização do precariado no Brasil e em Portugal, tentaremos identificar algumas das conexões decorrentes da atual onda de mercantilização do trabalho, como constituintes de movimentos sociais que, por meio da retomada de algum tipo de controle sobre seu meio social mais imediato, buscam atingir domínios sociais mais distantes, desafiando a mitologia de uma crise totalmente alheia a qualquer forma de controle social.

Como veremos adiante, o efeito desses movimentos protagonizados pelo precariado urbano é desigual, mas, em geral, tem pressionado as formas tradicionais de organizações dos trabalhadores, sobretudo os sindicatos e os partidos políticos, na direção de lutas sociais mais amplas. Trata-se de uma transformação em termos de protagonismo político que, apesar de perder o foco na produção, alcançou certa relevância ao conectar-se à esfera da vida cotidiana das classes subalternas.

\section{O precariado artístico:}

empreendedor criativo ou trabalhador precário?

Entre as principais dificuldades identificadas pela crítica aos estudos do trabalho global no tocante ao suposto advento de um "novo espírito transnacionalista" operário, destaca-se a flagrante incapacidade do movimento sindical internacional em organizar os trabalhadores precários (Burawoy, 2010). Por isso, neste artigo, pretendemos problematizar, por meio de dois estudos de caso, a suposição de parte substantiva da literatura neopolanyiana de que o aprofundamento da globalização capitalista 
não apenas debilitaria a capacidade dos trabalhadores em responder à ameaça da mercantilização como também favoreceria a formação de um contramovimento de resistência em escala global capaz de anunciar uma nova era marcada pela proteção do trabalhador, a exemplo do que ocorreu com o fordismo internacional do pós-Segunda Guerra Mundial.

Para tanto, selecionamos analisar um setor especialmente localizado na interseção entre as dinâmicas da precarização do trabalho e da mercantilização dos direitos sociais, isto é, o trabalho artístico intermitente. Nossa escolha justifica-se, por inúmeras razões. Trata-se, antes de tudo, de um grupo de trabalhadores do setor de serviços, que não apenas tem sido agudamente atingido pela adoção de políticas de austeridade, aplicadas em diferentes contextos nacionais como resposta à crise da globalização iniciada em 2008, como, ao mesmo tempo, tem se mostrado muito afinado com os processos políticos de mobilização alternativos às formas tradicionais de organização classista, como, por exemplo, os sindicatos e os partidos políticos. Além disso, os processos de mobilização social que iremos analisar no Brasil e em Portugal, tendo por base o trabalho artístico intermitente, favorecem a compreensão das relações problemáticas entre o precariado e o movimento sindical, ou seja, exatamente o eixo sobre o qual se apoiam os dilemas contemporâneos, identificados pelos novos estudos do trabalho global, no tocante às possíveis alternativas aos avanços do neoliberalismo em escala mundial.

Finalmente, a comparação entre realidades nacionais específicas permitirá problematizar o desenvolvimento desigual da crise capitalista contemporânea, assim como as diferentes respostas políticas dos trabaIhadores precários num contexto notoriamente marcado pela multiplicação dos conflitos sociais relativos à aplicação das políticas de austeridade pelos governos neoliberais. Esperamos que essa articulação contribua para compreendermos, de forma mais precisa, os alcances e os limites 
da transnacionalização das reivindicações dos trabalhadores em parte do chamado Sul global.

Em primeiro lugar, vale lembrar a observação de Marcel van der Linden (2013), fartamente demonstrada por estudos históricos comparativos, de que a condição proletária não é formada exclusivamente por aqueles trabalhadores que executam tarefas estandardizadas nas fábricas e usinas, mas, antes, radica na realidade no processo de concentração da terra e do capital que transformou tanto a agricultura tradicional quanto a pequena manufatura. Assim, é possível falarmos em um processo de proletarização do artista e do intelectual, definido a partir do aumento no número de trabalhadores sem controle sobre os meios de produção e que dependem da mercantilização de seu trabalho para sobreviver.

Desse modo, grande parte dos artistas partilha com os operários ou com os trabalhadores agrícolas a situação de quem não tem meios de produção nem capacidade de explorar o trabalho de outros. É a partir dessa constatação que surge a noção de "trabalhadores-artistas", uma categoria que tomamos emprestada do coletivo "Dolores Boca Aberta Mecatrônica de Artes" e que se refere àqueles que têm consciência da sua condição de trabalhador, atuando estética e politicamente a partir dessa condição.

A esse respeito, cabe observar que a sociologia brasileira acumulou um conjunto de estudos dedicados à análise das transformações nos modos de regulação e racionalização do trabalho em artes e espetáculos, com especial atenção aos músicos e aos bailarinos (Segnini, 2015). Trata-se de um conjunto de estudos de profissões selecionadas no campo da cultura, que priorizaram as mudanças em curso no mercado de trabalho balizado pela mercantilização e pela flexibilização do trabalho. Além disso, esses estudos têm privilegiado, tal como nosso esforço investigativo, a análise comparativa internacional entre políticas públicas, mercado e organização do trabaIho, com ênfase nos casos de Brasil e da França (Reis, 2012). 
Acompanhamos a afirmação de Pierre-Michel Menger, segundo a qual cada vez mais as atividades de criação artística se assumem como "(...) a expressão mais avançada dos novos modos de produção e das novas relações de emprego engendradas pelas mutações recentes do capitalismo" (2005, p. 44). O trabalho do artista é fortemente marcado pela instabilidade laboral, pela intermitência e pelo risco, de tal forma que a literatura sobre o trabalho artístico aponta a incerteza como a categoria-chave para a compreensão desse objeto².

Além disso, outra figura marcante do trabalho artístico é o chamado empreendedor criativo, responsável por todo o processo de produção e circulação de sua obra até alcançar o "cliente" final. Trata-se de um sujeito que explora a si mesmo e, nesse sentido, transforma-se em uma figura emblemática do neoliberalismo, exigindo que os produtores sejam cada dia mais adaptáveis e polivalentes, além de responsáveis por sua própria formação e capazes de administrar seu "capital individual" (Dardot; Laval, 2016) ${ }^{3}$.

Os dados relativos ao trabalho artístico em Portugal e no Brasil evidenciam o peso da precariedade laboral no setor, corroborando as análises de Menger. Uma característica que se destaca é a existência, no seio da população ativa, de taxas mais elevadas de trabalho autônomo entre os artistas. No Brasil, a participação dos trabalhadores por conta própria é substancialmente maior nas atividades relacionadas à cultura - 31,9\%, em 2012 - do que no total das atividades produtivas - 20,7\%, em 2012

\footnotetext{
${ }^{2}$ A incerteza coloca-se não apenas na perspectiva da continuidade/intermitência do trabalho, mas também como parte do processo criativo, cujo resultado é sempre incerto, pois o trabalho artístico afasta-se das atividades rotineiras e controláveis e porque o seu sucesso depende não apenas do artista, mas também do público, dos pares, dos críticos, etc.

3 Em suma, a produção artística pode ser interpretada como precursora do processo de flexibilização contratual, da jornada e das condições de consumo do trabalho associado à insegurança, à intermitência e à ausência de proteções sociais, servindo para revelar dinâmicas da precarização do trabalho que se expandem para o conjunto dos trabalhadores, inclusive para aqueles setores historicamente mais estáveis e protegidos, elevando o artista à condição de figura emblemática do trabalhador na era da globalização (Menger, 2005).
} 
(IBGE, 2013). Simultaneamente, a tendência de aumento da formalização do trabalho verificada na economia brasileira, em especial, na última década, foi acompanhada no setor cultural, passando de 34,4\% do total de ocupados com carteira assinada na cultura, em 2007, para 39,8\%, em 2012 (ibidem).

No caso português, os dados dos censos indicam que o número de empregados no setor cultural foi reduzido em quase 50\% entre 2001 e 2011, enquanto as situações de empregador, de trabalhador por conta própria e "outras situações" aumentaram de forma acentuada (Cena, 2016). Também aqui a participação dos trabalhadores por conta própria (situação enquadrada pelo regime de "recibos verdes", isto é, de trabaIhadores supostamente "independentes") é substancialmente maior nas atividades relacionadas à cultura $(25,6 \%$ em 2011$)$ do que no total das atividades produtivas $(6,6 \%$ em 2011). Acrescente ainda a prevalência de um vasto número de trabalhadores (cerca de 60\%) que retiram um rendimento mensal (proveniente de salários e/ou cachês) abaixo do Salário Mínimo Nacional (ibidem).

Os dados disponíveis revelam a notável presença da flexibilidade no setor, o que impõe aos trabalhadores-artistas: “(...) alternâncias de períodos de trabalho, de desemprego indenizado, de desemprego não indenizado, de procura de emprego, de gestão de redes de interconhecimentos, e de multiatividade dentro ou fora da esfera artística" (Menger, 2005, p. 103). A isso, deve-se acrescentar, tanto no caso português como no brasileiro, a permanente existência de períodos marcados por estágios sub-remunerados, contratos subvencionados, situações de subemprego e de empreendedorismo, crescentemente incentivados pelas políticas públicas para o setor.

Nesses momentos, os trabalhadores distanciam-se dos direitos trabaIhistas mais elementares, como a licença médica, as férias remuneradas, o 
13. ․ salário, a licença maternidade etc., assumindo individualmente todos os riscos inerentes à atividade profissional. O próprio Estado, seja o português ou o brasileiro, tem desempenhado um papel ativo no desmanche dos direitos trabalhistas e na construção de formas precárias de trabalho, quer por meio de cortes orçamentários para a área da cultura, quer pela terceirização da gestão pública, com a transferência de atribuições estatais, recursos e equipamentos públicos para as organizações sociais de caráter privado (OS).

\section{Dinâmicas da ação coletiva do precariado artístico no Brasil e em Portugal}

3.1 A conquista do programa de fomento ao teatro na cidade de São Paulo: o caso do "Arte contra a Barbárie"

Sentindo-se pouco representados pelos sindicatos e suas formas tradicionais de negociação, a ação coletiva dos trabalhadores-artistas brasileiros tem adquirido maior protagonismo fora das formas tradicionais de organização trabalhista (Romeo, 2015). No final da década de 1990, a recusa perante a orientação neoliberal do Estado brasileiro, aquém dos compromissos básicos com os direitos da cidadania, notadamente, no tocante ao apoio às artes, acirrou o debate entre um conjunto de agentes e coletivos teatrais da cidade de São Paulo, que decidiram se reunir em assembleias para discutir a conjuntura política e as necessidades específicas dos grupos de teatro, denunciando a intermitência e o subemprego no setor. Além disso, estes coletivos criticavam a mercantilização imposta ao setor da cultura, assim como o elitismo das políticas públicas baseadas, primordialmente, não no financiamento público direto, mas na Lei Rouanet ${ }^{4}$.

\footnotetext{
${ }^{4}$ Trata-se de uma lei de 1991, que estimula o investimento privado em cultura por meio de incentivos fiscais às empresas, deslocando para os setores empresariais as decisões-chave em ter-
} 
Na sequência de um conjunto de encontros entre integrantes dos grupos Companhia do Latão, Folias d'Arte, Monte Azul, Parlapatões, Pia Fraus, Tapa, e Teatro União e Olho Vivo (TUOV), os participantes foram afinando suas estratégias de mobilização, desembocando no primeiro Manifesto Arte contra a Barbárie, lançado em maio de 1999, que pretendia:

Marcar uma posição de esquerda diante da questão cultural no Brasil e, para tanto, contrapunha ao consenso dos integrados algumas verdades desviantes, como a lembrança de que a arte não é um mero produto cultural e que a cultura, por sua vez, não é simples matéria de fomento e patrocínios (Arantes, 2004, p. 222).

Em primeiro lugar, o movimento defendia a democratização da cultura e da produção artística, destacando a função social da arte. Além da ampla repercussão na cena teatral paulistana, o manifesto gerou debates entre os trabalhadores-artistas, angariou novos integrantes e produziu uma considerável sistematização de dados sobre os investimentos públicos e privados na área da cultura. Diante da ausência de resposta dos órgãos públicos, federais e municipais, a mobilização social dos trabalhadores-artistas intensificou-se em 1999 e 2000, por meio de lançamento de outros dois manifestos que atualizaram a primeira experiência.

Inspirados pelo estudo das legislações de fomento à produção cultural de diferentes países, os trabalhadores-artistas redigiram um projeto de lei baseado na convicção de que a sua produção teatral, não alinhada aos critérios mercantis, era merecedora da alocação de recursos públicos muni-

mos dos projetos apoiados. Assim, as empresas escolhem aqueles projetos que oferecem maior retorno de marketing ou que estão ancorados em relações de nepotismo com os diretores das empresas, de tal forma que 3\% dos proponentes captam cerca de 50\% dos recursos. Além disso, a aplicação da Lei Rouanet tem resultado também em fortes desequilíbrios regionais, uma vez que a maioria dos recursos fica concentrada na região Sudeste que, em 2011, reteve $68,1 \%$ dos projetos aprovados, correspondendo a $76,7 \%$ do valor total atribuído, enquanto, no extremo oposto, a região Norte captou menos de 1\% dos recursos. Disponível em: http:// www.cultura.gov.br/documents/10883/13170/Mecanismo-de-Incentivo-Fiscal-do-PRONAC. pdf/72996b45-97c4-443e-8268-38d1ee7cd199. Acesso em: 23 mai. 2014. 
cipais para a sua reprodução. O projeto desenvolvido por este processo de mobilização, com algumas modificações, foi aprovado pela Prefeitura de São Paulo no dia 6 de dezembro de 2000, garantindo uma notável vitória para o movimento dos trabalhadores-artistas da cidade de São Paulo.

Finalmente, a Lei Municipal de Fomento ao Teatro (Lei no 13.279) foi promulgada no dia 8 de janeiro de 2002, beneficiando-se da eleição à época de um projeto político "democrático-popular" para a prefeitura de São Paulo. Essa conquista constituiu um momento decisivo na historiografia dos grupos teatrais paulistanos, não apenas devido ao ineditismo em termos de apoio público ao teatro, mas, sobretudo, pela ênfase na pesquisa e na democratização da produção teatral ${ }^{5}$. Com a promulgação da Lei Municipal de Fomento ao Teatro, o poder público paulistano: “(...) Foi obrigado a pôr dinheiro num sujeito histórico que não é o mercado, numa outra forma de organizar e estruturar a produção, o núcleo artístico como trabalho continuado" (Moreira, 2012, p. 24).

Dessa forma, o movimento Arte contra a Barbárie gerou uma aguda transformação no teatro paulistano, cujo modo de produção engajado, reconhecido e apoiado pelo poder público, não se tornou hegemônico, mas passou a desafiar as relações sociais e de produção cultural dominantes, enfrentando as inúmeras tensões localizadas na interseção entre a dependência do financiamento, a autonomia artística e a radicalidade política:

Nós estamos numa sociedade capitalista onde o que impera é a relação social convertida em relação de mercadoria, portanto para a gente ser viável nós temos que nos converter em mercadorias, ou ser produtor de mercadorias para vendê-las no mercado. Então o que é que poderia ser mercadoria para quem faz teatro? Peças de teatro, você vai e vende as peças de teatro. Como é que se sustenta um co-

\footnotetext{
${ }^{5}$ Como observou Kinas (2010), a democratização dá-se tanto pela política de ingressos a preços baixos ou gratuitos, quanto pela criação das condições para um trabalho sistemático de pesquisa estética que não se limita a reproduzir os conteúdos codificados pelo mercado cultural ou mesmo pelo envolvimento das comunidades no processo de produção teatral.
} 
letivo de 20, às vezes 30 pessoas, produzindo algo que possa custear suas vidas? É um custo muito alto, sei lá, 2.000 reais para cada pessoa, para jogar o custo de vida bem lá para baixo, com precariedade... Se a gente for jogar 3.000, para não ser tão precário, aí já pode pagar um aluguel, mas morando com outro, dividindo... 3.000 contos para 20 pessoas dá 60.000 por mês, para um ano dá... 720.000. Como é que banca a autonomia econômica disso? Então este tipo de organização está fadado a não existir. Claro, tem o caráter militante que nos torna bastante resistentes, a gente consegue operar algum tempo sem nenhum recurso, mas não que não padeça toda uma ação, ela sofre fraturas, decadências e tal. (Coletivo Dolores, entrevista concedida em 13 de outubro de 2015).

Evidentemente, esse movimento não é alheio à precariedade que assola os trabalhadores do setor da produção cultural e artística: "Somos trabalhadores precários na forma de uma intermitência sem regra, sendo essa nossa efetiva condição prática" (Azevedo, 2011, p. 132).

Por outro lado, apesar do espírito da lei de fomento e do movimento que esteve na sua origem, ao entrar para a esfera das políticas públicas, e tendo em vista as exigências de contrapartidas sociais, os coletivos de teatro são levados a gerenciar o recurso público, correndo o risco de cair na armadilha do consentimento e do desmanche da crítica:

Num território sensível, populações vulneráveis devem ser preferencialmente governadas pela geração de 'oportunidades' e oferta de dispositivos 'pacificadores'. Pois a cultura, nesse meio tempo, tornou-se um precioso meio de governo, reunindo as duas funções: não só acalma os nervos, que, a esta altura, andam à flor da pele (economias emergentes intensificam tanto o trabalho quanto a sua falta), como pode, vez por outra, abrir as portas para o subemprego, intermitente, porém sublimado pela aura artística. Nada disso é pouca coisa, pelo contrário: menos, todavia, pela falta de recursos mobilizados e apropriados do que pelo pau na máquina da reprodução social, que de tão prodigiosa em 
seu funcionamento atual, gera legitimação e consentimento mesmo quando gira em falso. Aqui o nervo da armadilha em que o teatro de grupo se deixou apanhar, e não tinha como evitar (mesmo fazendo o certo na hora certa), desde o momento histórico em que a luta social, na falta de melhor escoadouro, foi sendo canalizada para a arena altamente regulada e vigiada das políticas públicas - de resto, consensuais, todo o mundo quer (Arantes, 2004, p. 206).

De qualquer maneira, a observação dos coletivos teatrais paulistanos e de seus espetáculos e intervenções, permitiu-nos salientar seu forte engajamento social, não apenas na promoção de relações horizontais e partilhadas com o público e com as comunidades onde estão inseridos, mas também no seu intenso envolvimento com os movimentos sociais urbanos, tal como ocorreu durante as chamadas Jornadas de Junho de 2013, além do notório envolvimento de alguns coletivos teatrais com o Movimento dos Trabalhadores Sem Terra (MST). Assim, esses grupos apropriam-se de forma criativa dos repertórios de ação coletiva dos movimentos sociais subalternos, tais como ocupações, passeatas, manifestações etc., além de trazerem para sua obra artística as questões relacionadas à exploração econômica, à discriminação racial, ao patriarcado e outras formas de opressão.

Esses coletivos têm fortalecido a criação de um contramovimento às ameaças da mercantilização do espaço urbano, em âmbito local, alinhado à vivificação das lutas sociais urbanas, tal como pudemos observar em campo a partir de junho de 2013 (Marques, 2016). Por outro lado, é importante destacar que a estratégia prioritária de interpelação do governo local, a fim de defender os direitos da cidadania e a produção cultural não-mercantilizada das comunidades, impõe uma flagrante limitação em termos de transnacionalização da ação coletiva desses trabalhadores precários.

Finalmente, no caso brasileiro, um padrão análogo pode ser verificado nos movimentos sociais urbanos protagonizados pelo precariado e 
próximos aos coletivos artísticos que atuam na mesma chave de "negociação conflitiva" com os governos locais, como é o caso do Movimento dos Trabalhadores Sem Teto (MTST), por exemplo. Nesse sentido, é possível dizer que a mesma dinâmica de ação coletiva traspassa tanto o movimento dos trabalhadores-artistas quanto o movimento dos trabalhadores sem-teto, sugerindo uma interação dialética que merece ser mais bem investigada no futuro.

\subsection{Contra o ataque aos direitos sociais e trabalhistas em Portugal: o caso do sindicato-movimento "Cena"}

Fortemente atingido pela crise financeira e econômica iniciada em 2008, Portugal mostrou-se um caso paradigmático dos avanços da mercantilização e da consequente precarização do trabalho no sul da Europa. Além disso, o país assistiu de forma pioneira o surgimento de contramovimentos de resistência, notoriamente os novos movimentos de jovens trabalhadores desempregados e subempregados, organizados em torno de inovações estratégicas e da decorrente formação de novas coalizões trabalhistas, como o movimento "Que se lixe a Troika!" e os movimentos de trabalhadores precários, como o Precários Inflexíveis (PI), por exemplo (ver Soeiro, 2015).

Em inúmeras ocasiões, os protestos de rua protagonizados por esses jovens superaram em número as marchas organizadas pelos sindicatos oficiais $^{6}$, favorecendo a aproximação entre o tradicional sindicalismo por-

\footnotetext{
${ }^{6}$ No entanto, em termos de impacto efetivo das mobilizações dos movimentos, ou seja, de sua capacidade para desafiar as rotinas econômicas e atingir a infraestrutura pública, as ações dos principais sindicatos foram prevalecentes. Vale ainda acrescentar que Portugal também está na vanguarda do movimento grevista europeu contra as medidas de austeridade em escala transnacional: "Em 14 de novembro de 2012, aconteceu a primeira greve europeia transnacional deste tipo (greve geral política). No entanto, ela foi efetiva apenas em Portugal e na Espanha. O objetivo das greves de massas é denunciar o caráter antidemocrático da administração política da crise e denunciar o fato de que a população trabalhadora estar pagando por uma crise que ela não causou" (Nowak; Gallas, 2014, p. 306).
} 
tuguês - em especial, aquele ligado à Confederação Geral dos Trabalhadores Portugueses (CGTP) - e os novos movimentos de jovens trabalhadores precarizados, como ilustra o caso da transformação de uma associação de trabalhadores precarizados da cultura em um sindicato, o Cena (Sindicato dos Músicos, dos Profissionais do Espetáculo e do Audiovisual).

Em Portugal, tendo em vista os sucessivos cortes no orçamento público destinado ao fomento da produção artística e cultural, os trabalhadores-artistas vivem sistematicamente numa situação de precariedade. Além disso, cabe destacar tanto a redução geral dos salários, verificada ao longo dos últimos anos (frequentemente abaixo do salário mínimo nacional, mesmo recorrendo à pluriatividade), quanto a multiplicação de vínculos precários, em que o regime de "recibos verdes" constitui a regra, implicando que os encargos sociais são suportados pelos próprios artistas. Finalmente, é possível observar com muita frequência situações de ilegalidade decorrentes do recurso aos "falsos" recibos verdes - ou seja, falsos trabalhadores independentes ${ }^{7}$ - e das estratégias de evasão fiscal e da falta de contribuição previdenciária.

No entanto, os cortes dos recursos orçamentários destinados à cultura, assim como a precarização geral dos direitos trabalhistas, tiveram como resultado o estímulo às diferentes formas de ação coletiva por parte dos artistas e dos coletivos artísticos portugueses, num momento em que o próprio movimento sindical português atravessava uma crise severa associada ao declínio das taxas de sindicalização (ver Soeiro, 2015). Em larga medida, as mobilizações dos jovens trabalhadores precários e, entre eles, dos trabalhadores-artistas, em Portugal, estiveram associadas tanto à luta contra o recuo dos direitos trabalhistas, quanto à defesa constitucional da democratização do acesso à cultura.

\footnotetext{
7 Situação em que os trabalhadores passam um recibo verde pela prestação de serviços como autônomos, quando na realidade trabalham subordinados a uma entidade patronal, cumprindo um horário, mas sem os direitos trabalhistas inerentes.
} 
Nesse contexto, um aspecto particular da experiência portuguesa é a expansão da atuação sindical na direção do setor artístico, por meio da criação, em 2011, do sindicato Cena que, a partir da incorporação do tradicional Sindicato dos Músicos (criado em 1909), alargou sua atuação para outras profissões relacionadas às artes e à cultura. Dessa forma, coroou-se o esforço organizativo, iniciado em 2006, com a criação da Plataforma dos Intermitentes do Espetáculo e do Audiovisual, além do

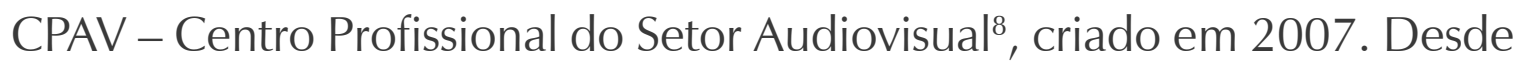
o início, o Cena apresentou-se como um projeto abrangente, filiando-se à CGTP e atuando em complementaridade com outras estruturas, como o STE (Sindicato dos Trabalhadores de Espetáculos) e a plataforma Plateia (Associação de Profissionais das Artes Cénicas).

O espírito colaborativo desse sindicato tornou-se ainda mais visível com a adesão de novos associados que, no início de 2016, alcançou o número de aproximadamente 1500 integrantes. Trata-se de uma expressiva quantidade de associados, se levarmos em conta a escala de um país como Portugal. Entre o vasto leque de questões e reivindicações assumidas pelo Cena, a direção atual (2016) destacou, em nossas entrevistas, como mais urgentes $^{9}$ : o aumento da regulamentação profissional dos trabalhadores do setor, respeitando as características particulares de cada uma das profissões que o compõem; o combate à precariedade do trabalho artístico, exigindo que o Código do Trabalho seja respeitado, notadamente através de contratos de trabalho efetivos e não contratos de prestação de serviços como trabalhadores independentes (falsos recibos verdes); o combate à terceirização; a democratização do acesso ao Ensino Artístico enquanto pilar fundamental da Educação; a revisão dos concursos de apoio à criação artística, de forma a que sejam assegurados os direitos trabalhistas; e,

${ }^{8}$ O CPAV era uma organização profissional dos setores do cinema, televisão e publicidade.

9 Para mais detalhes sobre a pesquisa de campo que subsidiou grande parte das afirmações contidas neste artigo, ver Marques (2016). 
finalmente, o aumento da proporção do orçamento do Estado português relativo à cultura com o objetivo de que este atinja $1 \%$ do PIB.

Por sua vez, entre as dificuldades enfrentadas pelo sindicato, a direção destacou a manutenção de taxas de sindicalização e queda da cotização num contexto de aumento acentuado do desemprego e de cortes nos salários e cachês, ao que se deve somar a condição de intermitência e de mudança constante de local de trabalho que também dificultou o enraizamento de muitos trabalhadores no setor:

O medo de deteriorar a sua relação no local de trabalho e de, por conta da enorme precariedade em que vivemos, podermos ser substituídos de forma fácil, acaba por retrair muitos trabalhadores na exigência dos seus direitos. Numa sociedade em que as pessoas são cada vez mais empurradas para o individualismo, também não se torna fácil remar contra esta forte maré de manipulação social e mostrar que a ação coletiva e a solidariedade entre pares é a forma mais eficaz de alcançar melhor condições de trabalho. Temos tentado mostrar aos trabalhadores do setor que um sindicato é feito por eles e que a sua atuação vai sempre de encontro às suas necessidades. Envolver cada vez mais os sócios no trabalho diário do Cena é fulcral para a solidificação do Sindicato na vida quotidiana dos locais de trabalho e para uma presença assídua no debate público (Dirigente do sindicato Cena, entrevista concedida em 14 de março de 2016).

Comparado ao sindicalismo tradicional, o Cena parece acompanhar a tendência de maior horizontalidade das diversas plataformas e movimentos às quais o sindicato alinhou-se. Além disso, o sindicato propõe-se desenvolver um novo sindicalismo com forte presença nas redes sociais, na articulação com os mais diversos movimentos sociais e plataformas de luta, de caráter local, nacional e transnacional, e abarcando a heterogeneidade de situações laborais existentes dentro do setor, considerando que:

É essencial a reconstituição da autonomia política ao nível de classe. Talvez já não tanto no sentido 'todos unidos a 
uma só voz' mas, provavelmente, fomentando a participação heterogénea para dar luz a novas ideias e à realidade do país (Sindicato Cena, Novos Rumos do Sindicalismo ${ }^{10}$ ).

Além disso, é importante destacar que tanto o Cena quanto as demais plataformas de mobilização dos trabalhadores-artistas a ele associadas dialogam com aquela primeira onda de mobilização do precariado europeu organizada em torno do movimento EuroMayDay (Soeiro, 2015). Assim, a despeito de suas iniciativas concentrarem-se na interpelação do Estado português, existe uma visível percepção entre os dirigentes e ativistas do sindicato, bastante saliente em nossas entrevistas, de que os problemas relacionados ao desmanche da proteção do mundo do trabalho no país, além dos cortes no orçamento do setor de cultura, não se esgotam no âmbito nacional. Ao contrário, a austeridade está diretamente relacionada ao contexto europeu.

Assim, o Cena pode ser interpretado como um autêntico representante do "sindicalismo de movimento social" (Moody, 1997) com flagrante vocação transnacionalista e que têm alimentado o marcante "otimismo neopolanyiano" dos estudos do trabalho global. Afinal, se as teorias ou modelos sindicais tradicionais, hierarquizados e burocratizados, apoiam-se em relações de negociação estáveis de longa data, essa estabilidade hoje não mais existe, ao mesmo tempo em que tem resultado no frequente isolamento das lutas dos trabalhadores de outros movimentos sociais democráticos, constituindo um obstáculo às reivindicações de proteção trabalhista.

Ao contrário das burocracias sindicais verticalizadas e acomodadas, o sindicalismo de movimento social anunciaria, como salientou Waterman (1993), a possibilidade da articulação dos trabalhadores sindicalizados com outras forças sociais (ecologistas, feministas, de direitos huma-

\footnotetext{
${ }^{10}$ Disponível em: <www.cenasindicato.org/quemsomos/novos_rumos_do_sindicalismo.html >. Acesso em: 20 jan. 2016.
} 
nos), além da combinação entre diferentes escalas de mobilização social em favorecimento de estruturas e relações sociais mais democráticas e cooperativas.

O Cena encaixa-se à perfeição nesta tendência e pode ser considerado um "sindicato-movimento" pela sua estrutura horizontalizada e descentralizada, pela sua atuação junto aos movimentos sociais e plataformas variadas de mobilização, pela heterogeneidade de situações laborais que acantona (ou seja, não apenas os trabalhadores assalariados, mas todo um conjunto de situações que tradicionalmente escapam à ação política organizada) e pelo internacionalismo das pautas (como, por exemplo, sua campanha em apoio às reivindicações dos "Intermitentes do Espetáculo" na França). Na articulação com outras plataformas de mobilização, o Cena uniu-se a um conjunto de movimentos sociais - tais como o Movimento 12 de Março, os Precários Inflexíveis, o Ferve e os organizadores do protesto da "Geração à rasca" no Porto, por exemplo - no combate à precariedade laboral, através de uma iniciativa legislativa de cidadãos por uma "Lei contra a precariedade" lançada em 2011 e que originou a Lei de combate aos falsos recibos verdes (Lei no 63/2013).

\section{Considerações finais}

Considerando o contexto social português contemporâneo, é perceptível um progressivo agravamento, motivado pela adoção de medidas de austeridade, das formas de precarização das condições contratuais e de trabalho, em especial, daqueles grupos de trabalhadores-artistas que dependem, em grande medida, de incentivos e ações governamentais. Esta situação acabou por promover uma aproximação íntima entre esses grupos e o repertório político característico do chamado "sindicalismo de movimento social", resultando em diferentes formas de ação coletiva 
pautadas por uma crescente aproximação dos trabalhadores-artistas portugueses com as mobilizações dos trabalhadores precários ${ }^{11}$.

Tanto no Brasil quanto em Portugal, a atual onda de neoliberalização do trabalho tem desafiado os sindicatos e os partidos políticos, que buscam proteger as classes subalternas dos impactos causados pelo aprofundamento das desigualdades, estimulado pela crise capitalista, com uma nítida degradação das condições de reprodução das classes trabalhadoras. Assim, o desenvolvimento desigual e combinado, entre a mundialização da divisão do trabalho e o aumento da desigualdade, exacerbou a alienação social das classes sociais subalternas, estimulando a transição de uma postura passiva desses grupos sociais precários na direção de uma atitude de desafio à mercantilização do trabalho.

O processo de mobilização dos trabalhadores-artistas precários nesses dois países permite-nos relativizar a contradição entre capital e trabaIho como a fonte básica das crises sociais e, consequentemente, a razão última das lutas políticas das organizações e movimentos anticapitalistas. Na realidade, outras fontes de conflito classistas acrescentam-se à contradição entre o capital e o trabalho, em um mundo cada dia mais marcado pelo ataque aos direitos sociais e trabalhistas. Assim, para além das mobilizações em torno das questões sindicais, os casos brasileiro e português revelam a importância da combinação das reivindicações trabalhistas com as formas de mobilização organizadas em torno da defesa dos direitos da cidadania, tal como o direito à cultura, por exemplo.

Afinal, a solução proposta pelas forças políticas neoliberais para a crise econômica atual consiste, basicamente, em privatizar os fundos públicos em detrimento dos direitos sociais. Nesse sentido, é possível afirmar

11 Essa aproximação tem singularizado os movimentos sociais que buscam intervir nas lutas redistributivas contemporâneas em uma conjuntura marcada pelo ataque sistemático aos direitos trabalhistas e previdenciários engendrado por aquilo que Harvey (2016) chama "política de acumulação por espoliação". 
que a espiral descendente das condições de vida dos trabalhadores precários continuará funcionando como um catalisador das insatisfações em relação às políticas de austeridade impostas aos trabalhadores. E a atual mobilização do precariado artístico no Brasil e, sobretudo, em Portugal, permite-nos identificar não apenas a vivificação de um sindicalismo de movimento social de trabalhadores pobres, informais, precários, imigrantes e desempregados, como também explorar formas inovadoras de ação coletiva para além dos limites nacionais.

Como é possível perceber por meio do desmanche da legislação trabalhista em Portugal e da proposta de reforma da previdência no Brasil, a evolução desigual e combinada da atual crise da globalização nesses dois países tem estimulado os setores financeiros a saquear os diferentes fundos públicos à custa dos direitos da cidadania garantidos pelas respectivas constituições nacionais pós-ditatoriais. O aprofundamento da tensão entre o regime de acumulação e o modo de regulação promovido pelo desaquecimento econômico global fez com que esses países experimentassem um aumento em larga escala da inquietação social de suas respectivas classes subalternas, em especial do precariado urbano.

Em Portugal, a ampliação do peso social do precariado urbano desafiou de forma bem-sucedida o corporativismo dos sindicatos. No Brasil, o saldo é menos positivo, mas, ainda assim, o precariado mostrou-se, em geral, uma força dinamizadora do movimento sindical, se tomarmos como referência a formação da Frente Povo Sem Medo liderada pelo MTST e com participação de vários sindicatos. As dinâmicas de mobilização dos trabalhadores-artistas em Portugal e no Brasil, analisadas neste artigo, sugerem que a agenda da proteção social organizada em torno da desmercantilização do trabalho e da luta por direitos sociais está longe de ter esgotado seu potencial político. 
Na realidade, a comparação entre os dois casos tratados neste artigo aponta para uma conclusão mais ou menos clara: o processo de mobilização dos trabalhadores precários alimenta-se da interação com um estilo de sindicalismo de movimento social que há muito tempo deixou de ser predominante tanto no Brasil quanto em Portugal. Em suma, apesar de ser inegável que os estudos do trabalho global padecem de uma perspectiva excessivamente otimista em relação ao surgimento de um contramovimento neopolanyiano em escala global, ao menos a pré-condição para o surgimento deste movimento é perceptível, tanto no Brasil como em Portugal: a formação de um movimento social inovador, protagonizado pelo precariado urbano.

Ruy Braga é Doutor em Ciências Sociais (UNICAMP) e Professor da Universidade de São Paulo, Faculdade de Filosofia Letras e Ciências Humanas, Departamento de Sociologia.

\ruy.braga@uol.com.br

Joana Marques é Doutorada em Sociologia pela USP. Colabora como assistente de pesquisa no Centro de Investigação e Estudos em Sociologia (CIES-IUL), Portugal, e no Centro de Estudos dos Direitos da Cidadania (CENEDIC).

¿joana.marques@usp.br

\section{Referências}

1. AGARWALA, R. Informal Labor, Formal Politics, and Dignified Discontent in India. Cambridge: Cambridge University Press, 2013.

2. ARANTES, P. E. Documentos de cultura, documentos de barbárie: o sujeito oculto de um manifesto. In: Zero à esquerda. São Paulo: Conrad, 2004, p. 221 235.

3. AZEVEDO, J. F. O processo teatro (notas para um programa de trabalho). In: ARAÚJO, Antônio; AZEVEDO, José Fernando Peixoto de; TENDLAU, Maria (orgs.). Próximo ato: teatro de grupo. São Paulo: Itaú Cultural, 2011, p. 130-139. 
Sociologias, Porto Alegre, ano 19, no 45, mai/ago 2017, p. 52-80

4. BEAUD, S.; PIALOUX, M. Retorno à condição operária: investigação em fábricas da Peugeot na França. São Paulo: Boitempo, 2009

5. BIELER, A; LINDBERG, I. Global restructuring, labour and the challenges for transnational solidarity. Londres: Routledge, 2010.

6. BRAGA, R; SANTANA, M. A. Dinâmicas da ação coletiva no Brasil contemporâneo: encontros e desencontros entre o sindicalismo e a juventude trabalhadora. Cadernos CRH, v. 28, n. 75, 2015.

7. BURAWOY, M. From Polanyi to Pollyanna: The false optimism of Global Labor Studies. Global Labour Studies, Hamilton, v. 1, n. 2, 2010.

8. CENA. Conclusões das reuniões na AR e resultados do Questionário, Mar. 2016. Disponível em: www.cenasindicato.org/noticias/entry. html?ref =268\&blog=noticias. Acesso em: 14 mar 2016.

9. DARDOT, P; LAVAL, C. A nova razão do mundo: ensaio sobre a sociedade neoliberal. São Paulo: Boitempo, 2016.

10. EVANS, P. National labor movements and transnational connections: global labor's evolving architecture under neoliberalism. Global Labour Journal, Hamilton, v. 5, n. 3, 2014.

11. HARVEY, D. 17 contradições e o fim do capitalismo. São Paulo: Boitempo, 2016.

12. IBGE [Instituto Brasileiro de Geografia e Estatística]. Sistema de Informações e Indicadores Culturais. Rio de Janeiro: IBGE, 2013.

13. KINAS, F. A Lei e o Programa de Fomento ao Teatro para a cidade de São Paulo: uma experiência de política pública bem-sucedida. Revista Extraprensa, v. 3, n. 3, 2010.

14. MARQUES, J. S. Trabalhadores-artistas: cenas de trabalho, organização e ação coletiva no Brasil e Portugal. São Paulo: Tese de Doutoramento, Universidade de São Paulo, 2016.

15. MENGER, P.-M. Retrato do artista enquanto trabalhador: metamorfoses do capitalismo. Lisboa: Roma Editora, 2005.

16. MOREIRA, L. C. There is no Alternative. In: DESGRANGES, Flávio; LEPIQUE, Maysa (orgs.). Teatro e vida pública: o fomento e os coletivos teatrais de São Paulo. São Paulo: Hucitec/ Cooperativa Paulista de Teatro, 2012, p. 15-27.

17. MOODY, K. Towards an international social-movement unionism. New Left Review, n. 225, 1997.

18. NOWAK, J.; GALLAS, A. Mass Srikes Against Austerity in Western Europe: A Strategic Assessment. Global Labour Journal, Hamilton, v. 5, n. 3, 2014. 
19. POLANYI, K. A grande transformação. Rio de Janeiro, Campus, 2000.

20. PRASHAD, V. The Poorer Nations: A Possible History of the Global South. London: Verso, 2012.

21. REIS, C. F. Projetos culturais e mercado de trabalho para jovens. Tese (Doutorado) - Universidade Estadual de Campinas, Campinas, 2012.

22. ROMEO, S. P. O movimento Arte Contra a Barbárie: gênese, estratégias de legitimação e princípios de hierarquização das práticas teatrais em São Paulo (19982002). 39. Encontro Anual da ANPOCS, Caxambu Set. 2015.

23. SANTOS, B. S.; COSTA, H. A. Para ampliar o cânone do internacionalismo operário. In: SANTOS, Boaventura de Sousa (org.). Trabalhar o mundo: os caminhos do novo internacionalismo operário. Rio de Janeiro: Civilização Brasileira, 2005.

24. SEGNINI, L. Os músicos e seu trabalho: diferenças de gênero e raça. Tempo Social, v. 26, n. 1, 2015.

25. SEIDMAN, G. Beyond the Boycott: Labor rights, human rights and transnational activism. New York: Russell Sage Foundation, 2008.

26. SEOANE, J.; TADDEI, E. From Seattle to Porto Alegre: The Anti-Neoliberal Globalization Movement. Current Sociology, v. 50, n. 1, jan. 2002.

27. SOEIRO, J. A formação do precariado: Transformações no trabalho e mobilizações de precários em Portugal. Tese (Doutorado) - Universidade de Coimbra, Coimbra, 2015.

28. VAN DER LINDEN, M. Trabalhadores do mundo: ensaios para uma história global do trabalho. Campinas: Editora da Unicamp, 2013.

29. WATERMAN, P. Trade Union Internationalism in the Age of Seattle. Antipode, v. 33, n. 3, pp. 312-336, jul de 2001.

30. WATERMAN, P. Social-Movement Unionism: a new model for a new world order. Review, v. 16, n. 3, p. 245-278, 1993.

31. WRIGHT, E. O. Envisioning Real Utopias. New York: Verso, 2010.

Recebido em: 27.12.2016

Aceito: 13.02.2017 